\title{
Interdisciplinary Full Mouth Rehabilitation in a Patient with High Aesthetic Demand
}

\author{
Simone Abhay Shah ${ }^{1}$, Deepak Nallaswamy ${ }^{2}$ \\ 1, 2 Department of Prosthodontics, Saveetha Dental College, Chennai, Tamil Nadu, India.
}

\section{INTRODUCTION}

Reconstruction of a worn-out dentition is a complicated task. Rehabilitation of the full mouth does not only rehabilitate the teeth, it also maintains a healthy stomatognathic system. ${ }^{1}$ A fully functional and biologically stable state between the teeth, the periodontal ligament (PDL), the muscles of mastication as well as the temporomandibular joint is obtained. ${ }^{2}$ All these mechanisms function together in harmony. The vertical dimension of occlusion is generally maintained by the tooth eruption and the alveolar bone growth. ${ }^{3}$ As the teeth wear, the alveolar bone adapts and compensates for the loss of tooth structure to maintain the vertical dimension of occlusion. ${ }^{4}$ Bruxism is one of the most common conditions leading to generalised tooth wear. It is a pathologic activity of the stomatognathic system involving tooth grinding during parafunctional movements. The clinical signs of bruxism are mostly related to tooth wear, temporomandibular joint (TMJ) and muscles discomforts. The main causative factors are local, systemic, psychological and hereditary factors. ${ }^{5}$ The correlation between bruxism, smoking habits and digestive disorders lead to serious consequences. ${ }^{6}$

This case report details the full mouth rehabilitation of a young patient with severely worn teeth and temporomandibular joint discomfort and pain. The patient was treated using a multidisciplinary approach involving a prosthodontist and a periodontist.

\section{PRESENTATION OF CASE}

A 25-year-old female patient reported to the Department of Prosthodontics at Saveetha Dental College with a chief complaint of pain in the muscles on chewing, generalised sensitivity and discoloured teeth. The patient was extremely conscious about her smile and had high aesthetic demands. She gave the history of habitual grinding of teeth and muscle pain in the night. Patient has no significant medical history.

The patient had a euryprosopic profile with a gummy smile. There was mild drooping of the corner of the lips, thus this suggested that there was a loss of vertical dimension. The patient had a straight profile (Figure 1). On examination of the temporomandibular joints, bilateral clicking was detected during opening and closing of the mouth. Patient had pain on palpation in the muscles of masticationmasseter and temporalis. To determine if the vertical dimension was altered the following criteria were evaluated $\mathrm{d}^{4,7,8,9}$

\author{
Corresponding Author: \\ Dr. Deepak Nallaswamy. \\ Director of Academics \\ Saveetha Institute of \\ Medical and Technical Sciences, \\ 162 Poonamallee High Road, \\ Chennai 600077, Tamil Nadu, India. \\ E-mail:drnallu@gmail.com
}

DOI: $10.14260 / \mathrm{jemds} / 2020 / 851$

How to Cite This Article:

Shah SA, Nallaswamy D. Interdisciplinary full mouth rehabilitation in a patient with high aesthetic demand. J Evolution Med Dent Sci 2020;9(51):3887-3891, DOI: 10.14260/jemds/2020/851

Submission 02-07-2020,

Peer Review 26-08-2020,

Acceptance 02-09-2020,

Published 21-12-2020.

Copyright (c) 2020 Simone Abhay Shah et al. This is an open access article distributed under Creative Commons Attribution License [Attribution 4.0 International (CC BY 4.0)] 
1. History of Wear: Patient had a habit of sleep bruxism, pain in the muscles of mastication and temporomandibular joint.

2. Phonetics: The interocclusal separation within $1 \mathrm{~mm}$ at the incisors leads to enunciation of the sound " $\mathrm{S}$ ". When there is an increase in the space the $s$ and $f$ sounds are altered. ${ }^{10}$

3. Interocclusal Space: Vertical dimension at rest as well as occlusion, difference in the space was $6 \mathrm{~mm}$. A freeway space of $2 \mathrm{~mm}$ is required for normal phonetics. Thus, there was a loss of $4 \mathrm{~mm}$ in the vertical dimension. ${ }^{11,12}$

4. Facial appearance: Drooping commissures around mouth was observed. ${ }^{11}$

\section{Intraoral Examination}

On Intraoral examination, she had generalised attrition wear facets present on all the teeth. Anterior deep bite, buttressing of the bone in the mandibular anteriors was seen due to occlusal trauma. Mild crowding in maxillary anterior teeth, buccally proclined 21 , overbite of $10 \mathrm{~mm}$ and over jet of $9 \mathrm{~mm}$. There was a discrepancy of around $2-3 \mathrm{~mm}$ between the centric relation and maximum intercuspation. (Figure 2). Orthopantomogram (OPG) of the patient showed generalised loss of enamel occlusally suggesting presence of multiple wear facets and generalised attrition. There was no vertical or horizontal bone loss seen. There was presence of impacted 38 and 48 (Figure 3).

\section{DISCUSSION OF MANAGEMENT}

On the first appointment, diagnostic casts were obtained. Following this the face bow transfer was completed. The vertical dimension was increased by $4 \mathrm{~mm}$. The centric relation position was recorded at the increased vertical dimension using computer-aided design (CAD) bite (Ivoclar Vivadent *Schaan) bite registration material and the casts were mounted on a semi adjustable articulator. Diagnostic wax up was made on the semi-adjustable articulator at the increased vertical dimension.

Following this, the patient was given an occlusal hard acrylic splint at $4 \mathrm{~mm}$ increase in vertical dimension. This occlusal splint was made according to Okeson's method. Only centric contact points were established (Figure 4). The patient was asked to use the splint for 6 weeks for symptomatic relief from the pain in the muscles of mastication. Crown lengthening with osseous recontouring in relation to 17 to 27 and 34 to 44 region was done to correct the gummy smile as well as to obtain sufficient clinical crown length (Figure 5). ${ }^{7}$ After a month of periodontal flap surgery, the tissues completely healed.

Tooth preparations were done in the maxillary and mandibular teeth (Figure 6). Double cord packing was done with 000 and 00 cords. Master Impressions were made using the two-step putty wash technique with Putty Elite HD Normal set (Zhermack; Italy) and Light body normal set Elite HD (Zhermack; Italy) (Figure 6). The jaw relation was recorded with maxillary and mandibular occlusal rims at an increased vertical dimension of $4 \mathrm{~mm}$.

Face bow record was taken using the UTS 3D (Ivoclar Vivadent). The die sectioned casts were mounted using the jaw relation record using the face bow on the Stratos 300 semiadjustable articulator. Cobalt chromium framework trial of the maxillary and mandibular teeth was done following this. The mandibular anteriors 33 to 43 were splinted together due to the reduced crown root ratio to provide stability. The rest of the teeth were given individual copings.

The ceramic framework trial was done with an established Class 2 mutually protected occlusion (Figure 7). Once the ceramic trial was satisfactory the crowns were glazed and cemented with glass ionomer cement (GC Gold Label, Japan) (Figure 8). A soft splint (night guard) was given to the patient to use every night. The patient was recalled every 3 months for check-up.
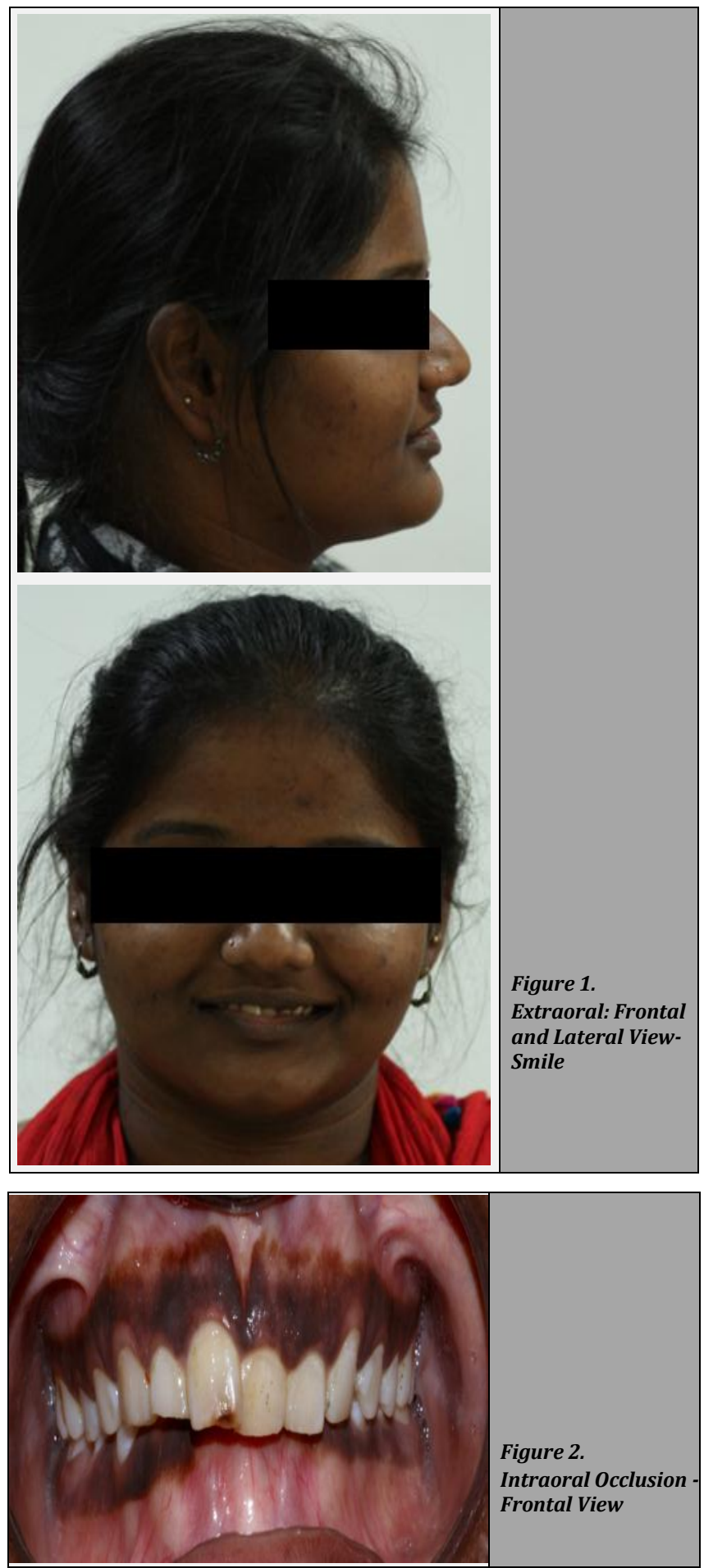

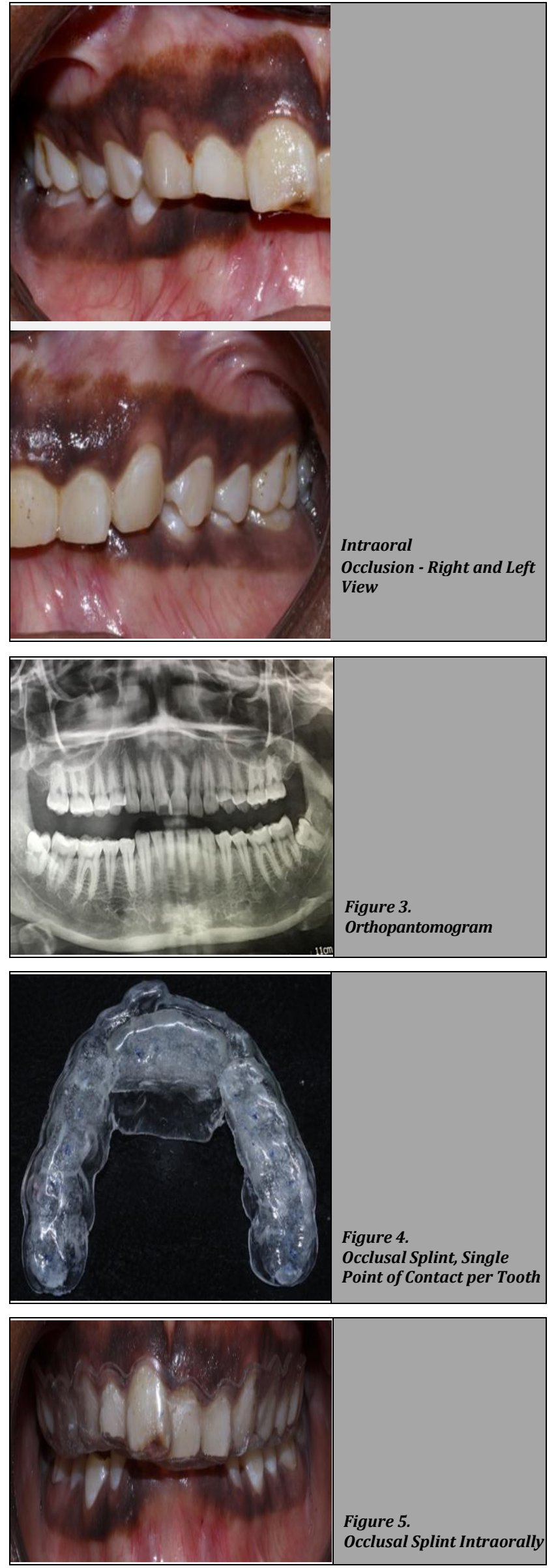
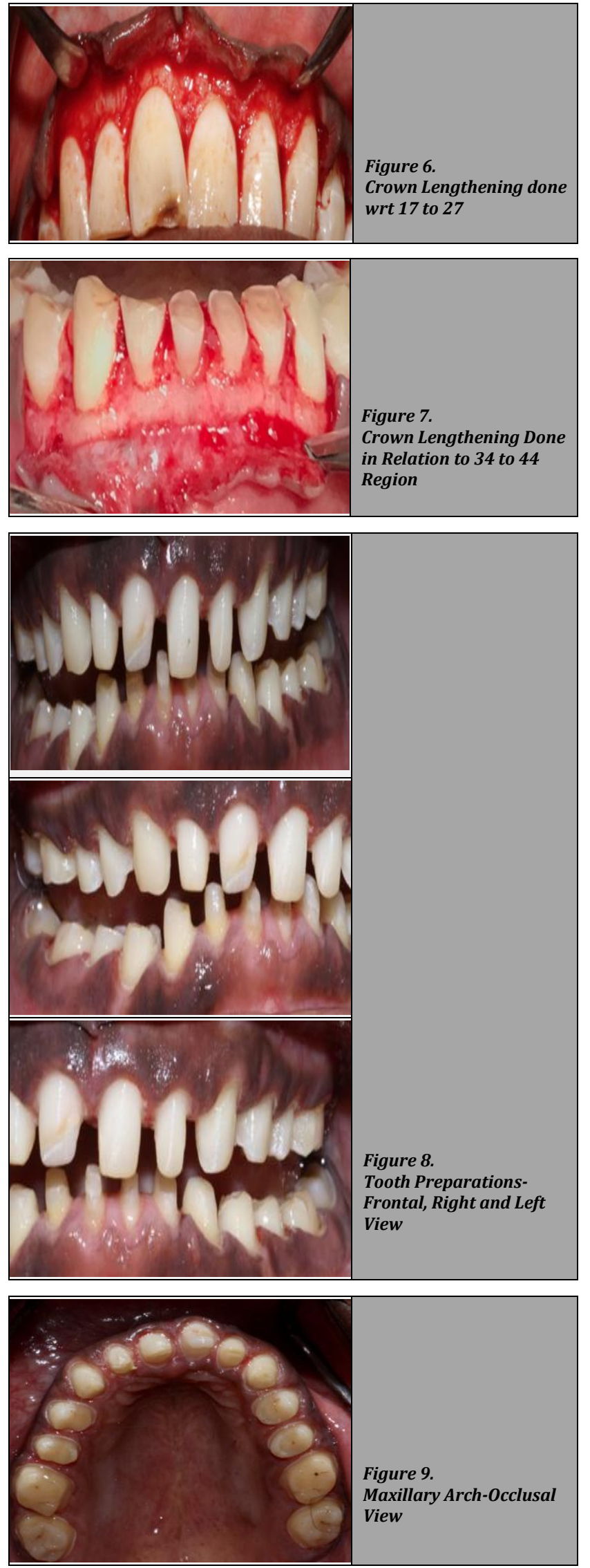

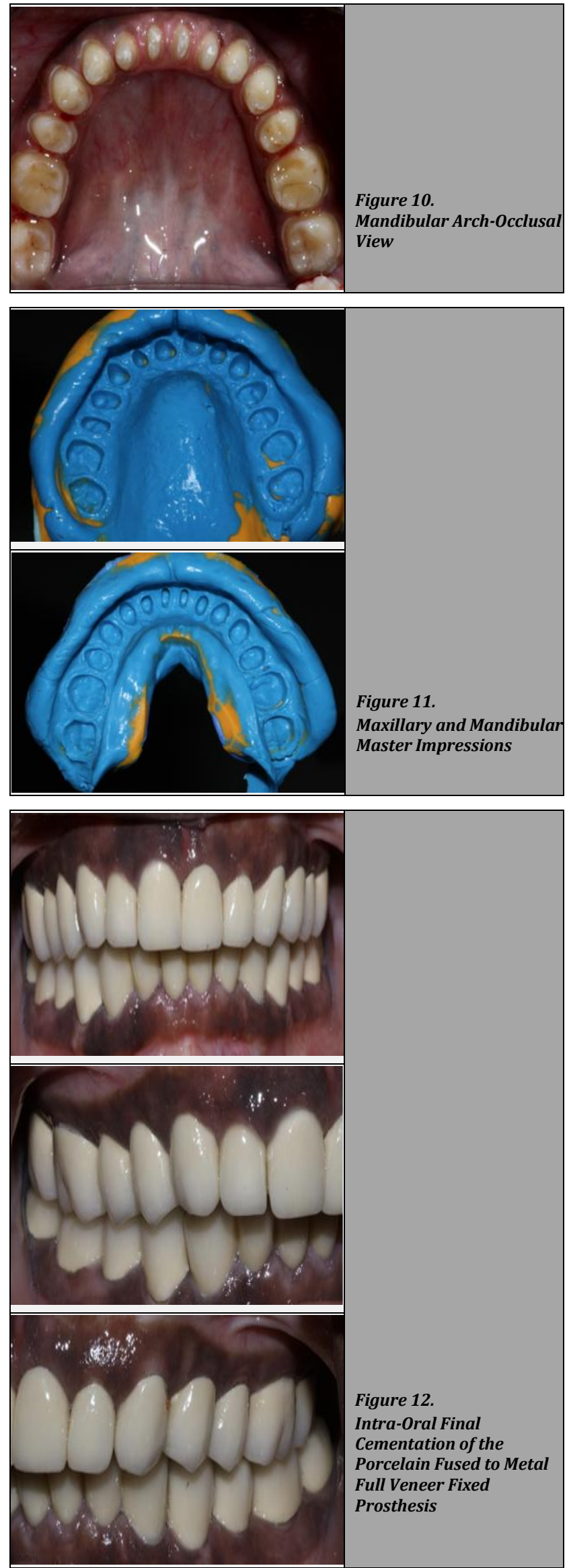
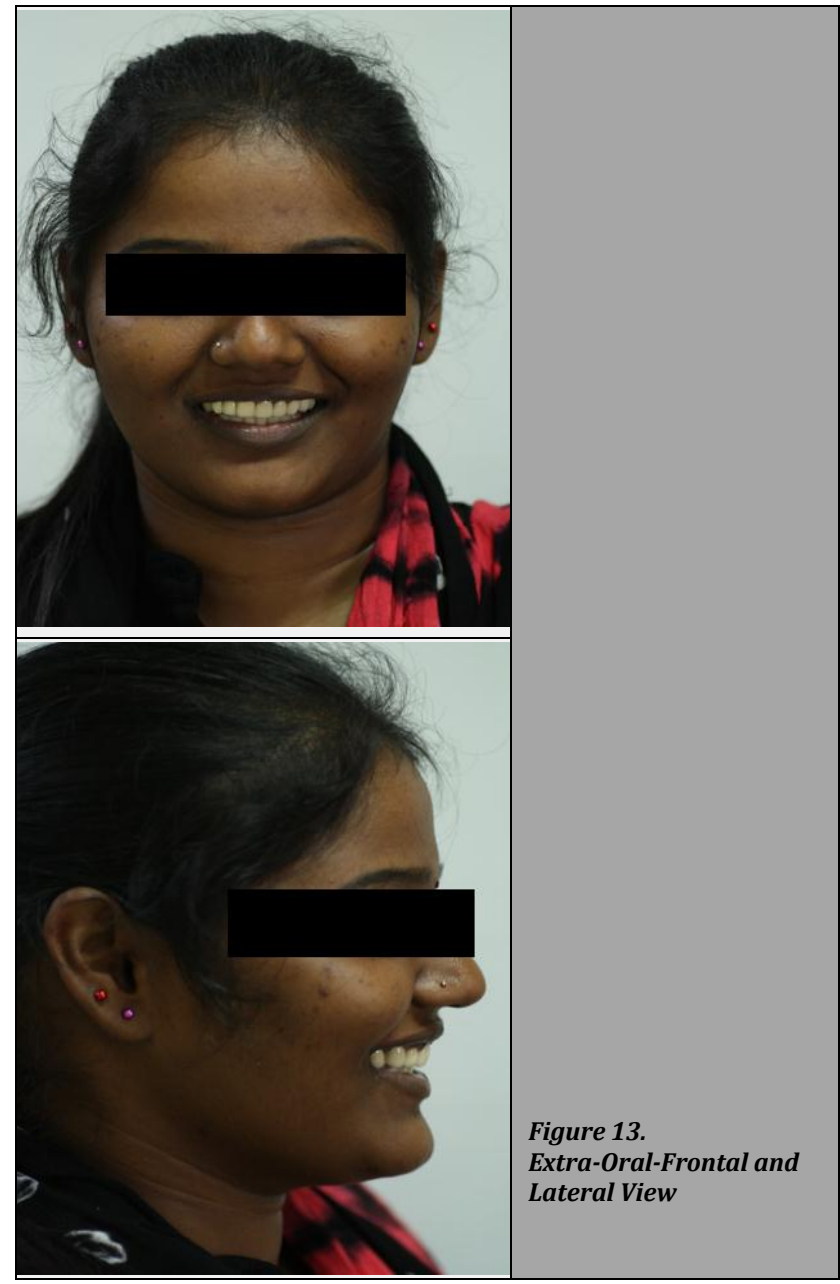

\section{DISCUSSION}

In 1984, Turner classified the treatment of a severely worn dentition by the amount of the loss of vertical dimension of occlusion and space available to restore. ${ }^{13}$ This classification included raising vertical dimension of occlusion (VDO) with multiple crown-lengthening procedures. ${ }^{14}$ The cause of tooth wear is multifactorial, and clinical controlled trials are limited in quantity and quality. The lack of evidence of the long-term treatment outcomes, further complicates clinical decisionmaking. ${ }^{15}$

The severe loss of vertical dimension in this patient was due to the sleep bruxism, hyperactive masseter muscles as well as the severe class 2 occlusion of the patient. ${ }^{16}$ This leads to detrimental effects on the tooth as well as the temporomandibular joint. ${ }^{17}$ At the start of the treatment the patient had a group function occlusion with no anterior guidance. ${ }^{18}$ This leads to continuous occlusal trauma to the posterior teeth due to continuous wear on contact. ${ }^{19}$ These challenges were overcome by increasing the vertical dimension of the patient by $4 \mathrm{~mm}$. This increased vertical dimension leads to a change in the patient's profile. The patient has been followed up for 2 years with no complaints.

A canine guided mutually protected occlusion was provided to the patient to reduce the load on the posterior teeth during excursive movements. 
The major advantage of this procedure would be the stepwise procedure keeping the patient's comfort in mind. Establishing an increased vertical dimension in the temporary restoration helped in replicating the same for the final restoration which was comfortable for the patient.

\section{CONCLUSIONS}

The management of patients with a severely worn out dentition is difficult. Thus, accurate diagnosis and radiographic examinations, diagnostic wax up and accurate determination of vertical dimension of occlusion are critical. Crown lengthening procedure exposes more clinical crown height improving the crown root ratio, which is necessary for a favourable prosthetic treatment. The fabrication and usage of an occlusal splint reduces the load on the temporomandibular joint and the muscles of mastication. This result can encourage clinicians to seek accurate diagnosis and treatment planning for such patients and treat them accurately.

Financial or other competing interests: None.

Disclosure forms provided by the authors are available with the full text of this article at jemds.com.

\section{REFERENCES}

[1] Goldman I. The goal of full mouth rehabilitation. The Journal of Prosthetic Dentistry 1952;2(2):246-51.

[2] Darraj A, Mattoo KA. Full mouth rehabilitation involving occlusal plane correction-case report. Journal of Medical Science and Clinical Research 2017;5(9):28204-8.

[3] Prasad S, Kuracina J, Monaco EA. Altering occlusal vertical dimension provisionally with base metal onlays: a clinical report. J Prosthet Dent 2008;100(5):338-42.

[4] Turner KA, Missirlian DM. Restoration of the extremely worn dentition. J Prosthet Dent 1984;52(4):467-74.

[5] Paesani DA. Bruxism: theory and practice. Quintessence Publishing Company 2010: p. 540.

[6] Madrid G, Madrid S, Vranesh JG, et al. Cigarette smoking and bruxism. Percept Mot Skills 1998;87(3 Pt 1):898.

[7] Hempton TJ, Dominici JT. Contemporary crownlengthening therapy: a review. J Am Dent Assoc 2010;141(6):647-55.

[8] Sowmya MK, Dandekeri S, Hegde C. Prosthodontic approach for restoration of extremely worn dentition: a case report. International Journal of Biomedical Research 2014;5(1):66-8.

[9] Şakar O, Sülün T, Kurt H, et al. Reliability and comparison of two facial measurements to detect changes of occlusal vertical dimension in complete denture wearers. Gerodontology 2011;28(3):205-8.

[10] Goldstein RE, Chu SJ, Lee EA, et al. Goldstein's esthetics in dentistry. John Wiley \& Sons 2018: p. 1576.

[11] Rebibo M, Darmouni L, Jouvin J, et al. Vertical dimension of occlusion: the keys to decision. International journal of Stomatology \& Occlusion Medicine 2009;2(3):147-59.

[12] Tavano KTA, Seraidarian PI, de Oliveira DD, et al. Determination of vertical dimension of occlusion in dentate patients by cephalometric analysis - pilot study. Gerodontology 2012;29(2):e297-305.

[13] Dawson PE. Functional occlusion from TMJ to Smile Design. Mosby Incorporated 2007: p. 630.

[14] Papaspyridakos P. Full mouth implant rehabilitation with staged approach: 6-year clinical follow-up. Journal of Esthetic and Restorative Dentistry 2015;27(4):213-23.

[15] Pasam N, Arora A, Gilra S. Full Mouth rehabilitation: a simple approach to a complex problem. LAP Lambert Academic Publishing 2012: p. 108.

[16] de Machado NAG, Fonseca RB, Branco CA, et al. Dental wear caused by association between bruxism and gastroesophageal reflux disease: a rehabilitation report. J Appl Oral Sci 2007;15(4):327-33.

[17] Podder A, Saha B, Saha AK, et al. A case of generalized tooth wear caused by bruxism and its rehabilitation. City Dental College Journal 2018;10(1):40-2.

[18] Bartlett DW. The role of erosion in tooth wear: aetiology, prevention and management. Int Dent J 2005;55(4 Suppl 1):277-84.

[19] Khan F, Young WG, Daley TJ. Dental erosion and bruxism. A tooth wear analysis from South East Queensland. Aust Dent J 1998;43(2):117-27. 